\title{
PAPERS
}

\section{Oesophageal cancer is an uncommon cause of death in patients with Barrett's oesophagus}

\author{
A van der Burgh, J Dees, W C J Hop, M van Blankenstein
}

\begin{abstract}
Background-Barrett's oesophagus carries a 30 -fold to 40 -fold increased risk of oesophageal cancer. It is unknown whether endoscopic surveillance programmes reduce mortality from oesophageal cancer.

Methods-A cohort study was undertaken of all 166 patients in whom the diagnosis Barrett's oesophagus had been established between 1973 and 1986.

Results-One hundred and fifty five of 166 patients could be traced $(93 \%)$. During a mean follow up of 9.3 years (amounting to 1440 patient years) eight patients had developed oesophageal cancer at random intervals (one case in 180 patient years). All but one of the tumours were diagnosed at endoscopy for symptoms, three in the stage of carcinoma in situ. Risk factors for the development of oesophageal cancer were extensive Barrett's oesophagus exceeding $10 \mathrm{~cm}(p=0.02)$ and Barrett's ulcer at the time of intake $(p=0 \cdot 009)$. Seventy six patients were alive; three had undergone surgery for oesophageal cancer and were without recurrence respectively, 12.8 years, $12 \cdot 1$ years, and 7 months postoperatively. Seventy nine patients had died; five of them had developed oesophageal cancer, but in only two cases this had been the cause of death $(2 \cdot 5 \%)$.
\end{abstract}

Conclusions-Oesophageal cancer is an uncommon cause of death in patients with Barrett's oesophagus. The patients of this cohort would not have benefited from an endoscopic surveillance programme.

(Gut 1996; 39: 5-8)

Keywords: oesophageal cancer, Barrett's oesophagus.

Barrett's oesophagus carries a 30 -fold to 40 fold increased risk of oesophageal cancer. The incidence has been estimated to be one cancer in 150 patient years. ${ }^{1-4}$ Therefore endoscopic surveillance has been widely advised. Although the costs and the workload are considerable, it is unknown whether mortality from oesophageal cancer is actually reduced.

We have not implemented a surveillance programme because it had been found in our previous study that there were serious reasons to doubt whether it would benefit patients with Barrett's oesophagus. ${ }^{2}$ However, as the mean follow up of the 155 patients in our investigation was limited to 4.4 years and because the status of the patients had essentially been ascertained by an enquiry to patients and general practitioners, a number of asymptomatic tumours could have been missed.

We therefore decided to re-evaluate the same cohort of patients eight years later to discover if the decision of refraining from endoscopic surveillance in unselected patients with Barrett's oesophagus was, in hindsight, justified. In addition, our aim was to learn more about the longterm natural history of patients with Barrett's oesophagus and to identify possible subgroups especially at risk for Barrett's carcinoma.

\section{Methods}

Patients

Included in the study were all 166 patients in whom the diagnosis of Barrett's oesophagus had been made during the period between November 1973 and May 1986. Additional entry criteria were: (a) Barrett's oesophagus over at least $3 \mathrm{~cm}$ of the full circumference, (b) patients with oesophageal cancer at that time were excluded, and (c) at least three months of follow up to avoid diagnostic problems arising from oesopheal strictures or ulcers in Barrett's oesophagus.

Data about the length of Barrett's oesophagus and the presence of Barrett's ulcer were obtained from the original endoscopy reports.

The general practitioners of the patients were questioned by post to find out if the patient was alive and if signs or symptoms of oesophageal cancer had developed. If necessary additional information was obtained by phone from either general practitioners, medical specialists or the patients themselves. To trace the whereabouts of patients who were no longer living at their original address, health insurers, population registries, relatives or clergymen were contacted and subsequently the general practitioner or specialists were contacted. In a number of cases extra data were found in the patient's records. If the patient had died, the date of death was 
obtained from either the general practitioner or the population registries while the cause of death was obtained from the records of the doctor treating at the time, usually the general practitioner.

In cases where oesophageal cancer had developed detailed information regarding endoscopy and histology reports, mode of treatment, and outcome was acquired through the medical specialists involved.

\section{Study design}

The length of follow up was calculated from the date of the first endoscopy at which the diagnosis Barrett's oesophagus was established until the date of the last information, usually either December 1994, or the date of death. The incidence of oesophageal cancer in this series of patients was calculated and this figure was compared with the expected incidence of an age and sex matched control group from the general population, taking into account the calendar year. ${ }^{5}$ The survival of this cohort of patients with Barrett's oesophagus was compared with the expected survival of the general Dutch population, matched for age and sex, taking into account the year of diagnosis (data from the Central Bureau of Statistics). Comparison of KaplanMeier curves was done using the log rank test. Cox regression was used to simultaneously evaluate the risk of oesophageal cancer in relation to both Barrett's ulcer and length of Barrett's oesophagus.

\section{Results}

\section{Incidence of oesophageal cancer}

As reported in our previous study 166 patients met the intake criteria. Their mean age at that time was 62 years (14-96 years). There were 97 men and 69 women. Adequate follow up data until December 1994 or the date of death could be acquired concerning 155 of 166 patients (93\%). Two patients were lost after 1986 and had an incomplete follow up, but two other patients not traced in 1986 were found. Therefore the present follow up percentage is the same as in 1986.

At the end of the follow up period 79 patients had died and 76 were alive. The total follow up amounted to 1440 patient years, the mean follow up was $9 \cdot 3$ years.

Eight oesophageal cancers had developed (four cases were already reported in our previous study and four additional cases were diagnosed after August 1986). The incidence of oesophageal cancer in this series was therefore one in 180 patient years, a 40-fold increased risk compared with an age and sex matched group from the general population.

The mean age at diagnosis Barrett's carcinoma for six men and two women was 67 years (52-81 years). The tumours were detected 12, $21,45,56,72,143,190$, and 191 months respectively after the endoscopic diagnosis of Barrett's oesophagus.

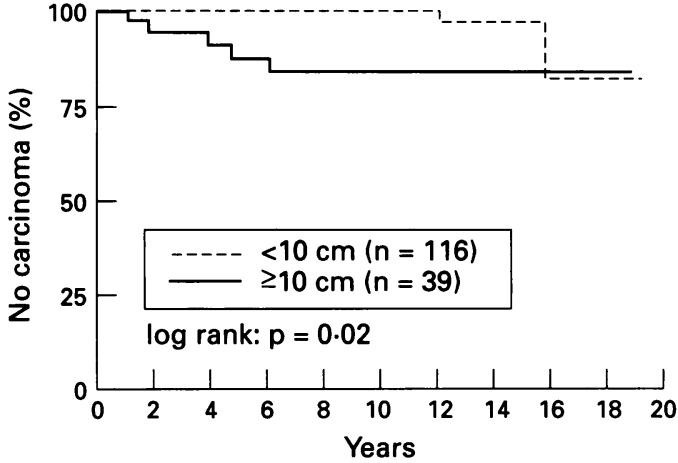

Figure 1: The Kaplan-Meier curves of the incidence of oesophageal cancer according to whether or not the length of Barrett's oesophagus exceeded $10 \mathrm{~cm}$.

\section{Characteristics of cancer patients}

The mean follow up period after the diagnosis Barrett's oesophagus was $7 \cdot 6$ years compared with 9.3 years in 147 patients in whom no Barrett's carcinoma had been diagnosed.

In the group of eight patients with Barrett's carcinoma the mean length of Barrett's oesophagus at first endoscopy was $9.4 \mathrm{~cm}$ compared with $6.6 \mathrm{~cm}$ in the group not developing Barrett's carcinoma. Figure 1 shows the Kaplan-Meier curves of the incidence of oesophageal cancer according to whether or not the length exceeded $10 \mathrm{~cm}(\mathrm{p}=0.02)$.

Highly interesting was the finding that six of eight patients had a Barrett's ulcer at first endoscopy (and one more later in the follow up period) compared with 37 in the other 147 patients. Figure 2 shows the Kaplan-Meier curves of the cancer incidence for the group with and without a Barrett's ulcer at intake $(p=0.009)$.

The length of Barrett's oesophagus and the presence of Barrett ulcer were independent risk factors according to multivariate analysis.

Thirteen per cent of patients with 3-5 cm of Barrett's oesophagus had a Barrett ulcer at first endoscopy, $25 \%$ of patients with $5-10 \mathrm{~cm}$ of Barrett's oesophagus, and $51 \%$ of patients with more than $10 \mathrm{~cm}$ of Barrett's oesophagus (Table I) $(\mathrm{p}<0.001)$.

In seven of eight patients the tumour was symptomatic: six complained of dysphagia and one of recurrent reflux symptoms. One tumour was diagnosed at endoscopic follow up in a patient still receiving treatment for reflux symptoms. Three patients had carcinoma in

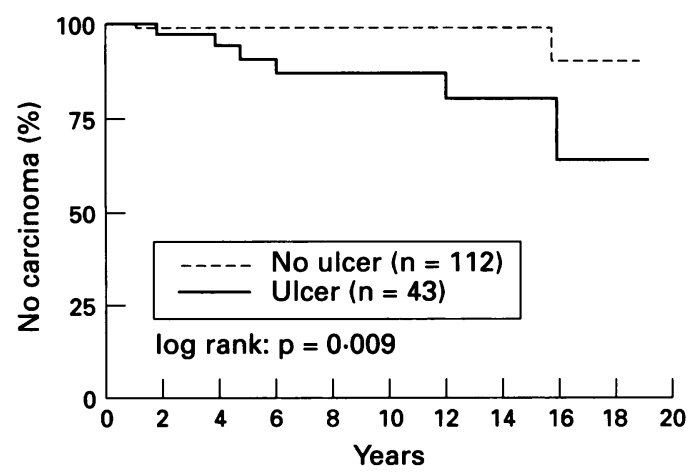

Figure 2: The Kaplan-Meier curves of the cancer incidence for the group with and without a Barrett's ulcer at intake. 
TABLE I Correlation between the length of Barrett's epithelium, Barrett's ulcer, and Barrett's carcinoma

\begin{tabular}{llccc}
\hline & & \multicolumn{3}{c}{ Length of Barrett's epithelium } \\
\cline { 3 - 5 } & & $3-4 \mathrm{~cm}$ & $5-9 \mathrm{~cm}$ & $>10 \mathrm{~cm}$ \\
& & $(n=53)$ & $(n=63)$ & $(n=39)$ \\
\hline Ulcer & $\mathbf{Y}(\%)$ & $7(13)$ & $16(25)$ & $20(51)$ \\
Cancer & $\mathbf{N}(\%)$ & $46(87)$ & $47(75)$ & $19(49)$ \\
& $\mathbf{Y}(\%)$ & $0(0)$ & $3(5)$ & $5(13)$ \\
& $\mathbf{N}(\%)$ & $53(100)$ & $60(95)$ & $34(87)$ \\
\hline
\end{tabular}

situ, five invasive cancer. One dysphagic patient, the patient with reflux symptoms, and the patient identified at screening all had carcinomas in situ, all diagnoses being confirmed in the resection specimens.

\section{Causes of death in patients with Barrett's} oesophagus

Six patients underwent surgical resection, among them all three with carcinoma in situ (CIS). Three patients were alive $12 \cdot 8$ years (CIS), $12 \cdot 1$ years, and 7 months postoperatively. Three others had died: one as a result of postoperative complications, one because of acute pancreatitis (CIS) 27 months postoperatively, and one patient with CIS died unexpectedly four years postoperatively because of liver metastases.

Two patients were not operated on: one refused treatment, whereas the other patient was considered unfit for surgery because of severely impaired pulmonary function and therefore was given brachytherapy. The first patient died $3 \cdot 2$ years later from myocardial infarction, the second patient died four months after with severe asthma.

Although five of eight patients with Barrett's carcinoma have died the cause of death could be linked to the oesophageal tumour in only two cases: one postoperative death and the case of liver metastasis after CIS. During the follow up period 79 patients died at a mean age of 75 years (34-99), but in only the two cases

TABLE II Causes of death of the 79 patients with Barrett's oesophagus who died during the follow up period

\begin{tabular}{lll}
\hline Cause of death & Patients $(n)$ & $\begin{array}{l}\text { Patients with } \\
\text { Barrett's } \\
\text { carcinoma }(n)\end{array}$ \\
\hline Myocardial infarction & 16 & 1 \\
Heart failure & 3 & \\
Cardiac disease & 7 & \\
Sudden death & 1 & \\
Cerebro-vascular accident & 4 & \\
Pneumonia & 4 & \\
Pulmonary disease & 5 & \\
Bronchogenic carcinoma & 5 & \\
Liver cirrhosis & 2 & \\
Variceal bleeding & 1 & \\
Acute pancreatitis & 1 & \\
Pancreatic carcinoma & 3 & \\
Papilla of Vater cancer & 1 & \\
Gastric carcinoma & 1 & \\
Colorectal carcinoma & 2 & \\
Mammacarcinoma & 2 & \\
Hepatic metastases & 1 & \\
Non-Hodgkin's lymphoma & 1 & \\
Multiple myeloma & 1 & \\
Paget's disease & 1 & \\
Postoperative bleeding & 2 & \\
Postoperative complications & 1 & \\
Sepsis & 2 & \\
Ileus & 1 & \\
Gangrene & 1 & \\
Old age & 1 & \\
Unknown (no symptoms of & 9 & \\
oesophageal cancer) & 9 & \\
\hline
\end{tabular}

described because of oesophageal cancer $(2.5 \%)$. Table II lists the other causes of death. None of these had signs or symptoms of oesophageal cancer. The expected mortality in an age/sex matched control population was 54 in contrast to the 79 deaths actually found. The standardised mortality ratio was therefore 79 : $54=1 \cdot 5$, resulting in an excess mortality of $50 \%$.

\section{Discussion}

This is the most extensive follow up study of patients with Barrett's oesophagus so far, comprising 1440 patient years. The incidence of oesophageal cancer in this series of 155 patients with a follow up of 9.3 years was one in 180 patient years, which is a 40 -fold increased risk compared with an age/sex matched group from the general population. This figure is in accordance with the incidence of one cancer in 170 patient years found in our previous study. ${ }^{2}$ The tumours developed at random intervals, which confirms the validity of the follow up technique.

During the follow up period 79 patients with Barrett's oesophagus died from a variety of causes, but only two fatalities were caused by oesophageal cancer $(2 \cdot 5 \%)$. Three other patients who died had developed Barrett's carcinoma, but died from unrelated causes. This confirms the data from the series published by Spechler and by Cameron that only half of the patients who develop Barrett's carcinoma actually die from this tumour. ${ }^{16}$

Although the mean age at death was 75 years, as in the studies of Spechler and Cameron, it should be noted that in this group of patients with Barrett's oesophagus an excess mortality of $50 \%$ was found. Table II shows the considerable mortality resulting from cardiac and pulmonary diseases, possibly related to the smoking and drinking habits of these patients. Other authors have also reported excess mortality although no comparison with a control population was made. In the series published by Miros 19 of 124 patients (mean age of 63 years) died during a mean follow up of 2.7 years, and in the series published by Spechler 16 of 105 patients (mean age of 58 years) died during a mean follow up of 3.3 years. ${ }^{1} 7$

Compared with endoscopic surveillance studies, cohort studies have the advantage of a high degree of ascertainment and a low degree of patient selection as no patient compliance is required. Therefore the natural history of patients with Barrett's oesophagus can be studied more reliably. The cancer incidence found in this series is very close to the incidence of one in 150 patient years calculated by Cameron from necropsy data. ${ }^{4}$

Had we implemented an endoscopic surveillance programme in our patients then some 1440 endoscopies would have been required to detect eight oesophageal cancers. It is highly unlikely, however, that any of these eight patients would have benefited from such a programme as without a formal surveillance they were either detected as CIS, responded well to surgery or died from unrelated causes. 
The results of the published surveillance studies show higher incidences of oesophageal cancer varying from one in 52 to one in 117 patient years, as might be expected as the result of selection/compliance. ${ }^{37-10}$ Three series have shown incidence figures decreasing as more patients are included. $3,119,1210,13$ Only four of 12 patients with Barrett's carcinoma detected in the three series published by Hameeteman, Miros, and Iftikhar underwent successful surgery, whereas in three other patients the life span was shortened as a result of postoperative death. In addition four patients were not operated on and one underwent unsuccessful palliation. The study by Williamson unfortunately does not mention the outcome of the five diagnosed cases of Barrett's carcinoma. Surprisingly, only half the carcinomas in these surveillance studies were detected as CIS. Few patients in fact benefit from surveillance programmes and it is unlikely that surveillance is more effective than alert intervention (endoscopy) for patients with Barrett's oesophagus developing dysphagia or recurrent pyrosis.

Several risk factors for developing Barrett's carcinoma have been identified, such as smoking and the length of Barrett's epithelium. ${ }^{3614}$ Important for surveillance programmes was the finding that Barrett's carcinoma virtually only develops in patients with dysplasia. ${ }^{7}$

This study confirms the length of Barrett's oesophagus as a risk factor (Fig 1); all tumours developed in a Barrett's oesophagus of more than $5 \mathrm{~cm}$ (Table I). In addition, our study strongly suggests a considerably increased risk in patients who have suffered from a Barrett's ulcer (Fig 2).

At intake endoscopy 43 of 155 patients had an ulcer in Barrett's oesophagus. Six of these 43 subsequently developed a cancer in Barrett's oesophagus compared with two of 112 without an ulcer $(p=0.009)$. It should also be noted that one of these two developed an ulcer in Barrett's oesophagus 4.6 years after intake and 11.3 years before carcinoma in Barrett's oesophagus. In total seven of eight cancer patients had experienced a Barrett's ulcer. Therefore it is probable that all but one of the Barrett carcinomas would have been detected if only patients with Barrett's ulcer had been kept under endoscopic surveillance. A reduction of the population at risk to one third of the original size could significantly increase the rationality and reduce the considerable costs of endoscopic surveillance programmes. ${ }^{15} 16$ The effectiveness could be further increased by excluding patients who are or become unfit for surgery and by improving methods of detecting more early cancers - that is, by making use of p53, flow cytometry, and other new techniques. ${ }^{17-19}$ This study has shown, however, that even the benefits of a surveillance programme for a subgroup of patients with Barrett's oesophagus who are particularly at risk remain to be verified as only few patients with Barrett's oesophagus actually die from oesophageal cancer.

1 Spechler SJ, Robbins AH, Rubins HB, Vincent ME, Heeren T, Doos WG. Adenocarcinoma and Barrett's esophagus. An overrated risk? Gastroenterology 1984; 87: 927-33.

2 Van der Veen AH, Dees J, Blankensteijn JD, van Blankenstein $\mathbf{M}$. Adenocarcinoma in Barrett's oesophagus: an overrated risk. Gut 1989; 30: 14-8.

3 Iftikhar SY, James PD, Steele RJC, Hardcastle JD, Atkinson $T$. Length of Barrett's oesophagus: an important factor in the development of dysplasia and adenocarcinoma. Gut 1992; 33: 1155-8.

4 Cameron AJ, Zinsmeister AR, Ballard DJ, Carney JA Prevalence of columnar-lined (Barrett's) esophagus: comparison of population-based clinical and authopsy findings. Gastroenterology 1990; 99: 818-22.

5 Visser O, Coebergh J, Schouten L, eds. Incidence of cancer in The Netherlands, 1991. Utrecht: Netherlands Cancer Registration, 1991

6 Cameron AJ, Ott BJ, Payne WS. The incidence of adenocarcinoma in columnar-lined (Barrett's) esophagus. N Engl F Med 1985; 313: 857-9.

7 Miros M, Kerlin P, Walker N. Only patients with dysplasia progress to adenocarcinoma in Barrett's oesophagus. Gut 1991; 32: 1441-6.

8 Hameeteman W, Tytgat GNJ, Houthoff HJ, Van de Tweel JG. Barrett's esophagus: development of dysplasia JG. Barrett's esophagus: development of dysplasia
and adenocarcinoma. Gastroenterology 1989; 96: 1249-56.

9 Williamson WA, Ellis FH, Gibb SP, Shahian DM, Aretz HT, Heatley GJ, et al. Barrett's oesophagus: prevalence and incidence of adenocarcinoma. Arch Intern Med 1991, 151: 2212-6.

10 Sampliner RE, Mackel C, Fennerty MB, Garewal HS Prospective incidence of cancer in Barrett's esophagus. Gastroenterology 1991; 100: A153.

11 Robertson CS, Mayberry JF, Nickelson DA, James PD, Atkinson $\mathbf{M}$. Value of endoscopic surveillance in the detection of neoplastic change in Barrett's oesophagus. $B r$ f Surg 1988; 75: 760-3.

12 Sprung DJ, Ellis FH, Gibb SP. Incidence of adenocarcinoma in Barrett's esophagus [abstract]. Am $\mathcal{F}$ Gastroenterol 1984; 79: 817 .

13 Sampliner RE, Kogan FJ, Morgan TR, Tripp $M$. Progression-regression of Barrett's esophagus [abstract]. Gastroenterology 1985; 88: 1567.

14 Mencke-Pluymers MBE, Hop WCJ, Dees J, van Blankenstein $M$, Tilanus $H W$. Risk factors for the development of an adenocarcinoma in columnar-lined (Barrett) oesophagus. Cancer 1993; 72: 1155-8.

15 Achkar E, Carey W. The cost of surveillance for adenocarcinoma complicating Barrett's oesophagus. Am Gastroenterol 1988; 83: 291-4.

16 Cameron AJ. Is the routine detection of CLE in a general population important? In: Giuli R, Tytgat GNJ, de Meester TR, eds. OESO. The oesophageal mucosa. 300 questions, 300 answers. Paris: 1993: 10-2.

17 questions, 300 answers. Paris: 1993: 10-2. Tilanus HW Prognostic value of p53 in Barrett's oesophagus. Eur $\dot{f}$ Gastroenterol Hepatol 1994; 7: 81-4.

18 Krishnadath $\mathrm{KK}$, Tilanus $\mathrm{HW}$, van Blankenstein $M$ Bosman FT, Mulder AF. Accumulation of p53 protein in normal, dysplastic, and neoplastic Barrett's oesophagus. f Pathol 1995; 175: $1-6$.

19 Reid BJ, Blount PL, Rubin CE, Levine DS, Haggitt RC, Rabinovitch PS. Flow-cytometric and histological progression to malignancy in Barrett's esophagus: prospective endoscopic surveillance of a cohort. Gastroenterology 1992; 102: 1212-9. 